\title{
Suitability of the eight-item version of the Brazilian Household Food Insecurity Measurement Scale to identify risk groups: evidence from a nationwide representative sample
}

\author{
Gabriela S Interlenghi,**, Michael E Reichenheim ${ }^{1}$, Ana M Segall-Corrêa ${ }^{2}$, \\ Rafael Pérez-Escamilla ${ }^{3}$, Claudia L Moraes ${ }^{1,4}$ and Rosana Salles-Costa ${ }^{5}$ \\ 'Department of Epidemiology, Institute of Social Medicine, Rio de Janeiro State University, Rua São Francisco Xavier \\ 524, $7^{\circ}$ andar/bloco D/sala 7018, 20550-013 - Maracanã, Rio de Janeiro, Brazil: ${ }^{2}$ Food, Nutrition and Culture \\ Program, Oswaldo Cruz Foundation, Brasília, Brazil: ${ }^{3}$ Department of Social and Behavioral Sciences, Yale School of \\ Public Health, New Haven, CT, USA: ${ }^{4}$ Medical School, Estácio de Sá University, Rio de Janeiro, Brazil: ${ }^{5}$ Department \\ of Social and Applied Nutrition, Nutrition Institute Josué de Castro, Federal University of Rio de Janeiro, Rio de \\ Janeiro, Brazil
}

Submitted 7 July 2018: Final revision received 29 0ctober 2018: Accepted 9 November 2018: First published online 27 December 2018

\begin{abstract}
Objective: The Brazilian Household Food Insecurity Measurement Scale (EBIA) has eight general/adult items applied in all households and six additional items exclusively asked in households with children and/or adolescents (HHCA). Continuing an investigation programme on the adequacy of model-based cut-off points for EBIA, the present study aims to: (i) explore the capacity of properly stratifying HHCA according to food insecurity (FI) severity level by applying only the eight 'generic' items; and (ii) compare it against the fourteen-item scale.

Design: Latent class factor analysis (LCFA) models were applied to the answers to the eight general/adult items to identify latent groups corresponding to FI levels and optimal group-separating cut-off points. Analyses involved a thorough classification agreement evaluation and were performed at the national level and by macro-regions.

Setting: Data derived from the cross-sectional Brazilian National Household Sample Survey of 2013.

Participants: A nationally representative sample of 116543 households.

Results: In all households and investigated domains, LCFA detected four distinct household food (in)security groups (food security and three levels of severity of FI) and the same set of cut-off points (1/2, 4/5 and 6/7). Misclassification in the aggregate data was $0.66 \%$ in adult-only households and $1.06 \%$ in HHCA. Comparison of the scale reduced to eight items with the 'original' fourteen-item scale demonstrated consistency in the classification. In HHCA, the agreement between both classifications was $96 \cdot 2 \%$.

Conclusions: Results indicate the eight 'generic' items in HHCA can be reliably used when it is not possible to apply the fourteen-item scale.
\end{abstract}

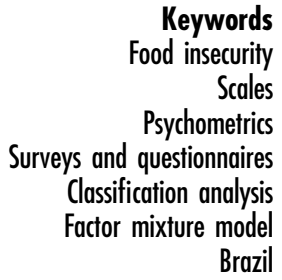

Brazil
Food and nutrition security issues have drawn worldwide awareness since the 1990s, as part of international efforts towards ensuring access to adequate food as a human right $^{(1,2)}$, and are now at the centre of global public agendas to fight hunger and poverty ${ }^{(3)}$. Assessing food insecurity is essential to this process, especially considering the negative impact of inadequate or even lack of food on health ${ }^{(4-8)}$.

Food security experience-based scales have been extensively used as a way to address food insecurity at the household level ${ }^{(9-13)}$. Resulting from a thorough crosscultural adaptation procedure of the US Household Food Security Survey Model (US-HFSSM) ${ }^{(14)}$ more than a decade ago $^{(15,16)}$, the Brazilian Household Food Insecurity Measurement Scale (Escala Brasileira de Insegurança Alimentar, EBIA) has since become the most widely used measurement tool, be it in nationwide surveys ${ }^{(17-21)}$ or targeted population-based studies ${ }^{(22-29)}$. It has been consistently shown that the instrument has strong psychometric validity ${ }^{(15,16,30-33)}$, reinforcing its suitability for monitoring and examining the determinants and 
consequences of food insecurity in at-risk and vulnerable households through prevalence surveys and observational studies $^{(10)}$.

Although initially comprised of fifteen items, the EBIA has undergone two revisions since its inception. One involved breaking down the question as to whether a '... member older than 18 years cut meal size or skipped meals...' into two, which resulted in an expanded sixteenitem version ${ }^{(18)}$. The second change occurred in 2014, when a Rasch analysis-based revision of the scale led to the current fourteen-item version ${ }^{(33,34)}$, in which the questions referring to '...member older than 18 years cut meal size...' and '...member older than 18 years lost weight...' were excluded. Inherent to instruments stemming from the US-HFSSM lineage, a common feature of the three versions is that the number of items answered depends on the presence or absence of individuals under 18 years of age. For instance, the current version comprises eight general/adult items applied in all households and six additional items if there are children and/or adolescents in the household ${ }^{(33)}$.

In parallel to the development of these different versions along the years, as well as several cross-cultural adaptations of the US-HFSSM lineage in many countries $^{(35-40)}$, there is a growing need to develop reduced versions of food security experience-based scales. A shorter version - possibly comprising a set of items that can be applied to all households - would be easier to apply in large-scale surveys, given that often there are limited financial and human resources as well as major time constraints for data collection ${ }^{(14,35,41)}$. Indeed, the FAO recently conducted a global standardization of an eight-item scale named the Food Insecurity Experience Scale (FIES) ${ }^{(42)}$. The instrument was based on the eight adult items from the Latin American and Caribbean Food Security Scale, which in turn was strongly informed by EBIA $^{(43)}$. FIES has now become the official food security scale for tracking one of the targets of the Sustainable Development Goals and has been applied in over 150 countries ${ }^{(44,45)}$. In the specific case of Brazil, it is important to consider that in 2014 an even more abbreviated version of EBIA which was comprised of five items was proposed for screening purposes ${ }^{(46)}$.

In addition to providing a continuous food insecurity score, the EBIA has also been operationalized categorically according to increasing groups of vulnerability, namely food security, mild, moderate and severe insecurity, as with the US scale ${ }^{(14)}$ since its conception $^{(15,16,33)}$. Focusing on monitoring, intervention and programme evaluation, the EBIA cut-off points were initially proposed for households with or without children and/or adolescents based on psychometric work and the experience from policy making. Accordingly, households with children and/or adolescents were proposed to be classified as mildly, moderately or severely food insecure if scoring 1-5, 6-9 and 10-14 points, respectively. The corresponding cut-off points for households where only adults lived were $1-3,4-5$ and $6-8$ points, respectively ${ }^{(33)}$. For both household composition scenarios, households were considered as food secure if none of the items were affirmed (i.e. score $=0$ ).

Recently, the initially proposed cut-off points were largely endorsed by two related studies based on latent class factor analyses (LCFA) ${ }^{(47,48)}$. Except for the cut-off point separating food security from mild food insecurity (where the model-based analyses consistently indicated that both scores 0 and 1 entailed food security rather than just 0 ), there was a good agreement between the two approaches regarding the other cut-off points, irrespective of household type. As with the originally proposed cut-off points, in the LCFA studies, the food insecurity categories were made directly comparable in households with and without children and/or adolescents. However, the downside was that fourteen items would still be required in households with children and/or adolescents, adding time and complexity to the interview process.

Therefore, an important question to answer is whether a single set of items can be used in any household, regardless of whether children and adolescents reside in it or not. Another important question is if the degree of food insecurity severity based on this item set administered in all households provides similar classification results as when EBIA is applied in full in accordance with the household's composition. Hence, the aim of the present study is to explore the psychometric performance of the eight general/adult-only items in this regard, i.e. in the classification of households with children and/or adolescents. Based on the model-based approach previously published by Reichenheim et $a l .{ }^{(47)}$ and Interlenghi et $a l .{ }^{(48)}$, the specific objective of the study is to identify adequate cut-off points for stratifying households according to FI vulnerability groups, especially with regard to households where individuals under 18 years of age live. The secondary objective is to compare the classification thus founded with that obtained when applying LCFA models to the complete fourteen-item version of the scale.

\section{Methods}

\section{Setting, study sample and the assessment of bousebold food insecurity}

Brazil is a heterogeneous country, territorially divided into five socioculturally and economically distinct macroregions: North, Northeast, Midwest, Southeast and South. The first two regions are formed by the least-developed municipalities, as shown by their lower average household incomes, levels of education and worst health outcomes, compared with the South, Southeast and Midwest regions ${ }^{(49)}$. Indeed, the latter regions have substantially lower food insecurity rates, compared with the North and Northeast regions ${ }^{(20)}$. 
The present study used data from the 2013 edition of the Brazilian National Household Sample Survey (Pesquisa Nacional por Amostra de Domicílios, PNAD), a periodic and nationally representative survey conducted by the Brazilian Institute of Geography and Statistics aiming to providing basic information for evaluating Brazil's social and economic development ${ }^{(20,50)}$. The PNAD-2013 employed a three-stage probabilistic clustersampling design, with the selection of municipalities in the first stage, census tracts in the second stage and households in the third stage ${ }^{(20,50)}$. The final sample comprised 116543 Brazilian households. A total of 58401 households had children and/or adolescents under 18 years of age living in them, and 58142 households had only adults (aged $\geq 18$ years). Details of the sample characteristics have been published previously by Interlenghi et al. ${ }^{(48)}$.

The survey applied the complete EBIA comprised by fourteen dichotomous items ('yes' or 'no'), of which six items apply only to households with children and/or adolescents ${ }^{(33)}$.

\section{Data analyses}

Following the analytical strategy developed by Reichenheim et $a l .{ }^{(47)}$ and Interlenghi et $a l .{ }^{(48)}$, the present study fitted LCFA models with the eight general/adult items of the EBIA with the aim to identify cut-off points able to accurately distinguish latent groups corresponding to different levels of food insecurity. Analyses were conducted both at the national level and by macro-regions of Brazil (i.e. North, Northeast, Southeast, South and Midwest).

It has been previously recommended that the first step for implementing LCFA models should involve ${ }^{(51)}$ : (i) separately detecting and using the best conventional confirmatory factor analysis and latent class analysis models as benchmarks; and (ii) fitting increasing complex $f$-factor, $k$-class LCFA models in the pursuit of a solution with the best fit and theoretical meaning. However, based on previous findings showing the one-factor, three-class and the one-factor, four-class models as the best solutions for $\operatorname{EBIA}^{(47,48)}$, it was decided to restrict model fit assessments and comparisons to these two models only. To this end, fit analyses considered the following statistical indices and parameters: (i) Bayesian Information Criterion, lower values indicating better model fit ${ }^{(52,53)}$; (ii) Vuong-LoMendell-Rubin likelihood ratio test, a statistically significant $P$ value $(P<0.05)$ between a $k$ - and a $(k-1)$-class LCFA model favouring the $k$-class more complex solution ${ }^{(54,55)}$; and (iii) entropy, to assess the quality of class separation (i.e. how well each latent class is distinguishable from the others) ${ }^{(53)}$, with values ranging from 0 (no class separation) to 1 (perfect class separation) ${ }^{(56)}$. As recommended by Clark et al. ${ }^{(51)}$, the decision on the best model also contemplated theoretical considerations in addition to the formal evaluation of fit.

Once the most suitable model was identified, the following LCFA parameters were obtained: (i) conditional item probabilities, which provide information on the probability of an observation (household) in a given class endorsing a specific item; and (ii) class probabilities, which concern the proportion of the population in a particular class ${ }^{(51)}$. These probabilities are next used to assign class membership and allocate households to their most likely latent class membership. Analyses to this point used the software Mplus $8 \cdot 1^{(57)}$ and accounted for the complex sampling structure of the data set.

The next step comprised ascertaining cut-off points to the overall raw score of the EBIA given the classes identified in the previous stage. For this purpose, raw scores were first computed by summing up item scores. Then, these raw scores were cross-tabulated with the classes specified according to the most likely membership assignment by the best LCFA model. This approach was used: (i) to detect optimal raw score cut-off points discriminating ordinal levels of food insecurity; and (ii) to examine the proportion misclassified. The analysis used the quadratic-weighted kappa coefficient $(\kappa \text { coefficient })^{(58,59)}$ to assess the degree of agreement between the model-based classification and the empirical grouping based on the identified raw score cut-off points. These analyses were conducted separately by household type (i.e. households with and without children and/or adolescents) and performed in the statistical software package Stata version 15.0 using the svy estimation command for survey data to allow for the complex sampling design ${ }^{(60)}$.

To meet the ancillary goal of comparing the EBIA classification originating from the eight general/adult items with the fourteen-item scale, we used the same empirical food insecurity groupings identified and outlined by Interlenghi et $a l{ }^{\left({ }^{(48)}\right.}$ on the identical population study. To this end, classifications obtained using LCFA based on the fourteen-item scale were merged with those resulting from our current analyses based on eight items.

\section{Results}

A preliminary evaluation of model fit comparing the threeclass and four-class solutions favoured the latter. Focusing on the aggregate data (i.e. Brazil total), although both models showed very high entropy values $(\geq 0.94)$, the four-class solution had a lower Bayesian Information Criterion (298029.9 v. 299 675.9) and a statistically significant Vuong-Lo-Mendell-Rubin likelihood ratio test $(P<0 \cdot 0001$; data not shown). For this reason, it was decided to conduct the ensuing analyses with the one-factor, four-class LCFA model.

Table 1 contains the estimated class probabilities of classes 1 to 4 (C1-C4) based on the eight-item EBIA, at the national level and by household type (the estimated class probabilities by macro-regions are presented in the online supplementary material, Supplemental Table 1). The percentages of households in the more severe classes of food 
Table 1 Percentage of households in each raw score for the eight general/adult items of the EBIA classified according to latent class membership identified through the one-factor, four-class LCFA model in the national sample, Brazil, PNAD-2013

\begin{tabular}{|c|c|c|c|c|c|c|c|c|c|c|c|c|}
\hline \multirow[b]{3}{*}{ Raw score } & \multicolumn{12}{|c|}{ Latent class (FI) } \\
\hline & \multicolumn{4}{|c|}{ Adult-only households } & \multicolumn{4}{|c|}{ Households with children and/or adolescents } & \multicolumn{4}{|c|}{ Total } \\
\hline & $\mathrm{C} 1$ & $\mathrm{C} 2$ & $\mathrm{C} 3$ & $\mathrm{C} 4$ & $\mathrm{C} 1$ & $\mathrm{C} 2$ & $\mathrm{C} 3$ & $\mathrm{C} 4$ & $\mathrm{C} 1$ & $\mathrm{C} 2$ & C3 & $\mathrm{C} 4$ \\
\hline 0 & 83.40 & 0 & 0 & 0 & $71 \cdot 20$ & 0 & 0 & 0 & $77 \cdot 40$ & 0 & 0 & 0 \\
\hline 1 & 4.55 & 0 & 0 & 0 & 7.40 & 0 & 0 & 0 & 5.95 & 0 & 0 & 0 \\
\hline 2 & 0 & 2.44 & 0 & 0 & 0 & 3.97 & 0 & 0 & 0 & $3 \cdot 19$ & 0 & 0 \\
\hline 3 & 0 & 2.38 & 0.03 & 0 & 0 & 4.16 & 0.06 & 0 & 0 & 3.25 & 0.04 & 0 \\
\hline 4 & 0 & $2 \cdot 17$ & 0.60 & 0 & 0 & 4.29 & 0.93 & 0 & 0 & $3 \cdot 21$ & 0.76 & 0 \\
\hline 5 & 0 & 0 & 1.42 & 0.01 & 0 & 0 & $2 \cdot 71$ & 0.02 & 0 & 0 & 2.00 & 0.01 \\
\hline 6 & 0 & 0 & 0.91 & 0.03 & 0 & 0 & 1.56 & 0.05 & 0 & 0 & 1.23 & 0.04 \\
\hline 7 & 0 & 0 & 0 & 0.81 & 0 & 0 & 0 & 1.36 & 0 & 0 & 0 & 1.08 \\
\hline 8 & 0 & 0 & 0 & 1.26 & 0 & 0 & 0 & 2.26 & 0 & 0 & 0 & 1.75 \\
\hline Total $^{*}$ & 88.0 & $7 \cdot 0$ & 3.0 & $2 \cdot 1$ & 78.6 & 12.4 & $5 \cdot 3$ & 3.7 & 83.4 & 9.7 & 4.0 & 2.9 \\
\hline
\end{tabular}

EBIA, Brazilian Household Food Insecurity Measurement Scale; LCFA, latent class factor analysis; PNAD-2013, Brazilian National Household Sample Survey of 2013; FI, food insecurity; C, class.

${ }^{*}$ Percentage of households in each class.

insecurity (C3 and C4) were about twice as high when comparing households with children and/or adolescents with those composed of adults only (9.0 v.5.1\%). Table 1 also presents the cross-classifications of the four latent classes specified by the best LCFA model and the raw scores. In both households with and without children and/ or adolescents, maximum discriminating inflection points were between scores 1 and $2(1 / 2), 4$ and $5(4 / 5)$ and 6 and $7(6 / 7)$. The same thresholds replicated in all macroregions (Supplemental Table 1).

Using these limits to specify cut-off points, Table 2 summarizes the degree of agreement/disagreement when contrasting the identified latent classes $\mathrm{C} 1-\mathrm{C} 4$ with the four-level variable grouped in this way. In the nationallevel data, misclassification percentages were 1.06 and $0.66 \%$ in households with and without children and/or adolescents, respectively, both consistent with the $\kappa$ coefficients which were close to $1 \cdot 0$. Classification disagreements between the fitted food insecurity latent classes and the ensuing grouping once applying the cutoff points ranged from $0 \cdot 16 \%$ (Southeast) to $1 \cdot 48 \%$ (North) in households with only adults, and from $0.22 \%$ (Midwest) to $2.40 \%$ (Northeast) in households with children and/or adolescents. Respective $\kappa$ coefficients were all larger than 0.95 .

Table 3 compares the EBIA food insecurity categories resulting from empirical groupings identified from the eight general/adult items for all households and the classification proposed by Interlenghi et al. ${ }^{(48)}$, based on the fourteen-item scale. Overall, the classification pattern in both approaches was consistent. As expected in the adultonly households (columns 2 to 5), there was no misclassification since the post-modelling FI categorizations were based on the same eight items in both approaches. Focusing on the households with children and/or adolescents (columns 6-9), classification agreement was

Table 2 Agreement/disagreement profile comparing the model-based cut-off points and the identified food insecurity latent classes based only on the eight general/adult items of the EBIA in the national sample and by macro-regions, Brazil, PNAD-2013

\begin{tabular}{|c|c|c|c|c|c|c|c|c|c|}
\hline \multirow[b]{3}{*}{ Country/region } & \multicolumn{9}{|c|}{ EBIA classification based on the eight general/adult items* } \\
\hline & \multicolumn{3}{|c|}{ Adult-only households } & \multicolumn{3}{|c|}{ Households with children and/or adolescents } & \multicolumn{3}{|c|}{ Total } \\
\hline & C-error† & $\kappa$ coefficient $\ddagger$ & $95 \% \mathrm{Cl}$ & C-error† & $\kappa$ coefficient $\ddagger$ & $95 \% \mathrm{Cl}$ & C-error† & $\kappa$ coefficientł & $95 \% \mathrm{Cl}$ \\
\hline Brazil & 0.66 & 0.969 & $0.967,0.972$ & 1.06 & 0.971 & $0.969,0.973$ & 0.86 & 0.971 & $0.969,0.973$ \\
\hline North & 1.48 & 0.956 & $0.948,0.964$ & 2.09 & 0.959 & $0.953,0.965$ & 1.85 & 0.958 & $0.953,0.963$ \\
\hline Northeast & 1.44 & 0.962 & $0.958,0.968$ & $2 \cdot 40$ & 0.957 & $0.952,0.961$ & 1.96 & 0.957 & $0.952,0.961$ \\
\hline Southeast & $0 \cdot 16$ & 0.989 & $0.985,0.992$ & 0.39 & 0.984 & $0.980,0.989$ & 0.27 & 0.986 & $0.983,0.989$ \\
\hline South & 0.66 & 0.957 & $0.947,0.967$ & 0.67 & 0.969 & $0.961,0.977$ & 0.67 & 0.964 & $0.957,0.970$ \\
\hline Midwest & 0.13 & 0.993 & $0.988,0.998$ & 0.22 & 0.992 & $0.988,0.996$ & 0.18 & 0.992 & $0.988,0.996$ \\
\hline
\end{tabular}

EBIA, Brazilian Household Food Insecurity Measurement Scale; PNAD-2013, Brazilian National Household Sample Survey of 2013; C-error, percentage of households misclassified (or reclassified).

*Model-based cut-off points for all household types (i.e. adult-only, with children and/or adolescents, and total): 1/2, 4/5 and 6/7.

†Sum of off-diagonal percentages for the aggregate data (Brazil) as shown in Table 1 and macro-regions; see text.

$\ddagger$ Quadratic-weighted values $(95 \% \mathrm{Cl})$ obtained via bootstrap $(B=1000)$ by using the Stata routine bootstrap, including clustering and sampling weights ${ }^{(59)}$. 
Table 3 Contrast between the post-modelling categorization of the eight general/adult items of the EBIA and the post-modelling categorization of the complete (fourteen-item) scale, by household type, in the national sample and by macro-regions, Brazil, PNAD-2013

\begin{tabular}{|c|c|c|c|c|c|c|c|c|}
\hline \multirow{3}{*}{$\begin{array}{l}\text { Post-modelling FI categorization based } \\
\text { on the eight general/adult items of the EBIA } †\end{array}$} & \multicolumn{8}{|c|}{ Post-modelling FI categorization based on the fourteen-item EBIA* } \\
\hline & \multicolumn{4}{|c|}{ Adult-only households } & \multicolumn{4}{|c|}{ Households with children and/or adolescents } \\
\hline & None & Mild & Moderate & Severe & None & Mild & Moderate & Severe \\
\hline \multicolumn{9}{|l|}{ Brazil } \\
\hline None & 87.96 & 0 & 0 & 0 & $78 \cdot 21$ & 0.42 & 0 & 0 \\
\hline Mild & 0 & $7 \cdot 61$ & 0 & 0 & 0 & $12 \cdot 15$ & 1.25 & 0 \\
\hline Moderate & 0 & 0 & $2 \cdot 36$ & 0 & 0 & 0.77 & 3.29 & 0.28 \\
\hline Severe & 0 & 0 & 0 & 2.07 & 0 & 0 & 1.09 & 2.54 \\
\hline $\begin{array}{l}\text { C-errorł } \\
\kappa \text { coefficient§ }\end{array}$ & \multicolumn{4}{|c|}{$\begin{array}{c}0 \\
1.0\end{array}$} & \multicolumn{4}{|c|}{$\begin{array}{c}3.81 \\
0.893(0.889,0.898)\end{array}$} \\
\hline \multicolumn{9}{|l|}{ North } \\
\hline None & $80 \cdot 04$ & 0 & 0 & 0 & $66 \cdot 3$ & 0.67 & 0 & 0 \\
\hline Mild & 0 & 11.34 & 0 & 0 & 0 & $16 \cdot 02$ & 1.67 & 0 \\
\hline Moderate & 0 & 0 & 4.22 & 0 & 0 & 1.38 & 5.63 & 0.57 \\
\hline Severe & 0 & 0 & 0 & 4.40 & 0 & 0 & 2.51 & $5 \cdot 26$ \\
\hline $\begin{array}{l}\text { C-error } \ddagger \\
\kappa \text { coefficient§ }\end{array}$ & \multicolumn{4}{|c|}{$\begin{array}{c}0 \\
1.0\end{array}$} & \multicolumn{4}{|c|}{$\begin{array}{c}6.8 \\
0.869(0.859,0.879)\end{array}$} \\
\hline \multicolumn{9}{|l|}{ Northeast } \\
\hline None & $77 \cdot 16$ & 0 & 0 & 0 & 63.46 & 0.64 & 0 & 0 \\
\hline Mild & 0 & $14 \cdot 31$ & 0 & 0 & 0 & $19 \cdot 85$ & 2.41 & 0 \\
\hline Moderate & 0 & 0 & 4.89 & 0 & 0 & 1.37 & $6 \cdot 08$ & 0.47 \\
\hline Severe & 0 & 0 & 0 & 3.64 & 0 & 0 & 1.63 & 4.09 \\
\hline $\begin{array}{l}\text { C-errorł } \\
\kappa \text { coefficient§ }\end{array}$ & \multicolumn{4}{|c|}{$\begin{array}{c}0 \\
1.0\end{array}$} & \multicolumn{4}{|c|}{$\begin{array}{c}6.52 \\
0.882(0.875,0.889)\end{array}$} \\
\hline \multicolumn{9}{|l|}{ Southeast } \\
\hline None & 92.56 & 0 & 0 & 0 & 87.04 & 0.27 & 0 & 0 \\
\hline Mild & 0 & 4.78 & 0 & 0 & 0 & $7 \cdot 82$ & 0.66 & 0 \\
\hline Moderate & 0 & 0 & 1.31 & 0 & 0 & 0.37 & 1.67 & 0.14 \\
\hline Severe & 0 & 0 & 0 & 1.34 & 0 & 0 & 0.58 & 1.44 \\
\hline $\begin{array}{l}\text { C-errorł } \\
\kappa \text { coefficient§ }\end{array}$ & \multicolumn{4}{|c|}{$\begin{array}{c}0 \\
1.0\end{array}$} & \multicolumn{4}{|c|}{$\begin{array}{l}2.02 \\
0.915(0.906,0.924)\end{array}$} \\
\hline \multicolumn{9}{|l|}{ South } \\
\hline None & 91.94 & 0 & 0 & 0 & 87.86 & 0.24 & 0 & 0 \\
\hline Mild & 0 & 5.41 & 0 & 0 & 0 & $7 \cdot 25$ & 0.55 & 0 \\
\hline Moderate & 0 & 0 & 1.40 & 0 & 0 & 0.47 & 1.34 & 0.16 \\
\hline Severe & 0 & 0 & 0 & 1.25 & 0 & 0 & 0.80 & 1.33 \\
\hline $\begin{array}{l}\text { C-errorł } \\
\kappa \text { coefficient§ }\end{array}$ & \multicolumn{4}{|c|}{$\begin{array}{c}0 \\
1.0\end{array}$} & \multicolumn{4}{|c|}{$\begin{array}{l}2.22 \\
0.901(0.887,0.914)\end{array}$} \\
\hline \multicolumn{9}{|l|}{ Midwest } \\
\hline None & 89.97 & 0 & 0 & 0 & 84.45 & 0.37 & 0 & 0 \\
\hline Mild & 0 & 6.51 & 0 & 0 & 0 & 9.93 & 0.76 & 0 \\
\hline Moderate & 0 & 0 & 1.80 & 0 & 0 & 0.40 & 1.97 & 0.22 \\
\hline Severe & 0 & 0 & 0 & 1.72 & 0 & 0 & 0.50 & 1.40 \\
\hline $\begin{array}{l}\text { C-errorł } \\
\kappa \text { coefficient§ }\end{array}$ & \multicolumn{4}{|c|}{$\begin{array}{c}0 \\
1.0\end{array}$} & \multicolumn{4}{|c|}{$\begin{array}{l}2.25 \\
0.916(0.902,0.930)\end{array}$} \\
\hline
\end{tabular}

EBIA, Brazilian Household Food Insecurity Measurement Scale; PNAD-2013, Brazilian National Household Sample Survey of 2013; FI, food insecurity; C-error, percentage of households misclassified (or reclassified).

${ }^{\star}$ Model-based cut-off points for adult-only households are 1/2, 4/5 and 6/7, whereas model-based cut-off points for households with children and/or adolescents are $1 / 2,5 / 6$ and $10 / 11$.

†Model-based cut-off points for adult-only households and households with children and/or adolescents are 1/2, 4/5 and 6/7.

$\ddagger$ Sum of off-diagonal percentages.

§Quadratic-weighted values $(95 \% \mathrm{Cl})$ obtained via bootstrap $(B=1000)$ by using the Stata routine bootstrap, including clustering and sampling weights ${ }^{(59)}$.

$96.2 \%$ for Brazil at large and ranged from $92.3 \%$ in the North region to $98.0 \%$ in the Southeast. By extension, $\kappa$ coefficients were about $0 \cdot 9$.

\section{Discussion}

The present study explored the classification of household food insecurity by considering only the eight general/adult items of the EBIA for all households and its implication in the classification of households with children and/or adolescents. Results indicated that the same cut-off points can be used across household types and country regions. Moreover, the classification of food insecurity in households with children and/or adolescents under the age of 18 years was similar regardless if the eight-item or the fourteen-item scale was used.

The percentage of households in each of the latent classes was consistent with the findings from Interlenghi et $a l .{ }^{(48)}$ on the one-factor, four-class LCFA model resulting 
from the analysis of the fourteen-item scale in the same data set. To illustrate, in households with children and/or adolescents, values for $\mathrm{C} 1$ to $\mathrm{C} 4$ in the former and the current study were very similar (78.2, 12.9, 6.25 and $2.7 \%$ $v$. $78 \cdot 6,12 \cdot 4,5 \cdot 3$ and $3.7 \%$, respectively). It is worth noting that the proportion of households classified in the more severe classes combined were almost identical in both analyses (8.95 v. 9.0\%, respectively). Also, as expected, the combined figures were higher in households with children and/or adolescents compared with those where only adults lived. It should be noted, however, that the prevalence of severe food insecurity (C4) was slightly higher in households with children and/or adolescents with the eight-item EBIA compared with the prevalence based on the fourteen-item scale obtained by Interlenghi et al. ${ }^{(48)}$ (3.7 v. 2.7\%).

Our findings also show, as anticipated, the ability to identify more severe cases of food insecurity in households with children and/or adolescents than in adult-only households despite using a reduced version devoid of items specifically covering the former age stratum. Added to the benefit of a smaller burden for the respondent when using eight items only, the shortened version may be included with confidence in large-scale studies and surveys where there are major time and financial constraints. The classification based on eight items is also more pragmatic given all households are classified using the same items irrespectively of household type. A drawback however is that policy makers involved in maternal-child or youth programmes may not feel as influenced by the eight-item scale as it does not include any child/adolescent-specific item. At any rate, it is relevant to consider that, from a functional standpoint, what matters is whether a scale is effectively able to detect an increasing intensity of the phenomenon under investigation, regardless of the items taken into account ${ }^{(61)}$. This apparently occurs with the abridged version under scrutiny.

Concerning the class-separating cut-off points, the now uniform thresholds detected in the current study $(1 / 2,4 / 5$ and $6 / 7$ ) were the same as those identified by Interlenghi et $a l .{ }^{(48)}$ for the adult-only Brazilian households. In that study, however, small discrepancies were found across some macro-regions for the thresholds of the most severe categories (from C3 to C4). Despite this, the authors concluded that these divergences would be inconsequential for categorizing households across FI levels, hence uniform cut-off points could be used for the country ${ }^{(48)}$. This was confirmed in the current study where a single set of cut-off points was identified in all the five macro-regions, irrespective of household composition.

As in the preceding studies applying the same methodology for the ascertainment of cut-off points for $\operatorname{EBIA}^{(47,48)}$, our findings in the current study indicated that households with one positive answer in the raw score should be grouped together with households who did not affirm any EBIA question. This contrasts with a reclassification of households from the mild food insecurity into the food security category in relation to the traditional classification in which only households with a raw score of 0 are considered as food secure ${ }^{(33)}$. This finding has been previously presented and discussed by Reichenheim et $a l .{ }^{(47)}$ and Interlenghi et $a l .{ }^{(48)}$.

In the present study, when comparing the empirical groupings based on the cut-off points identified from the eight-item EBIA with the fourteen-item scale, the FI classification of adult-only households was the same by design, whereas some amount of reclassification occurred in households with children and/or adolescents. Concerning the latter, however, this reclassification should be viewed symmetrically, since it is not possible to establish which approach gives the most adequate estimates. Regardless, there is strong overall classification consistency when either fourteen or eight EBIA items are used. As mentioned before, the model-based grouping using the eight-item version confirms that households with children and/or adolescents have higher prevalence of moderate and severe food insecurity compared with adultonly households.

As mentioned in the present paper's introduction, our study does not stand alone in pursuing an abridged version of the EBIA. A few years ago, a five-item version was proposed by Santos et al. ${ }^{(46)}$ as a screening tool. The authors endorsed this version based on showing acceptable sensitivity, specificity and accuracy as compared with the reference fifteen-item EBIA. While that effort was an important start to developing an abbreviated EBIA, that work needed to be extended to identify a reduced scale faithful to the metric and scalar properties of the full EBIA version. Our specific contribution substantially adds to knowledge in this area by identifying an abbreviated EBIA version that retains the structural psychometric properties from the full scale ${ }^{(31-33)}$, especially regarding its ability to properly discriminate among the four food insecurity groups (classes). Additionally, the eight-item version derived from our study has the advantage of including the entire set of EBIA adult items and thus being aligned with the FIES scale being used by FAO for global monitoring of food insecurity ${ }^{(42)}$.

\section{Conclusion}

To conclude, our findings clearly indicate that in households with children and/or adolescents it is appropriate to apply the eight-item EBIA. This has important implications for large-scale epidemiological studies as well as surveillance systems or repeated surveys. For instance, the eightitem version could be included in the Brazilian Food and Nutrition Surveillance System (Sistema de Vigilância Alimentar e Nutricional, SISVAN) ${ }^{(62,63)}$ or in health-related surveys, such as the Surveillance System of Risk and Protection Factors for Chronic Diseases by Telephone 
Survey (Vigilância de Fatores de Risco e Proteção para Doenças Crônicas por Inquérito Telefônico, VIGITEL) ${ }^{(64)}$. Therefore, it is important to elicit input on the eight-item EBIA from nutrition, food security and public health policy makers. Moving forward, we recommend replicating our model-based approach in future national surveys to verify the stability and consistency of the results. Additionally, exploring this approach in data sets from other countries involving similar scales would be also opportune. We also recommend assessing construct validity of the eight-item EBIA by examining theoretically expected associations between food insecurity and key socio-economic and demographic indicators, such as family income, level of education and occupation of the head of the family, and household composition.

\section{Acknowledgements}

Financial support: G.S.I. was supported by the Coordination for the Improvement of Higher Education Personnel (Coordenação de Aperfeiçoamento de Pessoal de Nível Superior, CAPES) (grant numbers PROEX-1405766 and BEX-10645/14-4). M.E.R. was partially supported by the Brazilian National Research Council (Conselho Nacional de Pesquisa, CNPq) (grant numbers 302224/ 2013-0 and 301381/2017-8). C.L.M. was supported by CNPq (grant number 302851/2008-9). R.S.-C. was supported by the Carlos Chagas Filho Research Support Foundation (Fundação Carlos Chagas de Apoio à Pesquisa do Estado do Rio de Janeiro, FAPERJ) (grant number E-26/ 103.296/2011). The funders had no role in the design, analysis or writing of this article. Conflict of interest: None. Authorship: G.S.I., M.E.R. and R.S.-C. designed the study, wrote the paper and had primary responsibility for the final content. G.S.I. and M.E.R. performed the statistical analyses. G.S.I. undertook the literature review and wrote the first draft of the manuscript. A.M.S.-C., C.L.M. and R.S.-C. contributed to the interpretation of results. R.P.-E. collaborated in the writing of the final version of the manuscript. All authors critically reviewed the manuscript. All authors read and approved the final manuscript. Ethics of buman subject participation: Ethical approval was not required for this paper. The study is based on secondary data analyses of unidentified public domain data collected through a national household sample survey under the auspices of the Brazilian Institute of Geography and Statistics, an institution from the Brazilian Government with the mandate to provide national statistics.

\section{Supplementary material}

To view supplementary material for this article, please visit https://doi.org/10.1017/S1368980018003592

\section{References}

1. Food and Agriculture Organization of the United Nations (1996) Rome Declaration on World Food Security. http:// www.fao.org/docrep/003/w3613e/w3613e00.htm (accessed January 2017).

2. Burity V, Francheschini T, Valente F et al. (2010) Direito Humano à Alimentação Adequada no Contexto da Segurança Alimentar e Nutricional (Human Right to Adequate Food in the Food and Nutrition Security Context). Brasilia, DF: Ação Brasileira Pela Nutrição e Direitos Humanos.

3. United Nations Sustainable Development Goals Knowledge Platform (2016) Transforming our world: the 2030 Agenda for Sustainable Development. https://sustainabledevelopment. un.org/post2015/transformingourworld (accessed December 2018)

4. Olson CM (1999) Nutrition and health outcomes associated with food insecurity and hunger. J Nutr 129, Suppl. 2, S521-S524.

5. Seligman HK, Laraia BA \& Kushel MB (2010) Food insecurity is associated with chronic disease among low-income NHANES participants. I Nutr 140, 304-310.

6. Hromi-Fiedler A, Bermúdez-Millán A, Segura-Pérez S et al. (2011) Household food insecurity is associated with depressive symptoms among low-income pregnant Latinas. Matern Child Nutr 7, 421-430.

7. Poblacion AP, Cook JT, Marín-León L et al. (2016) Food insecurity and the negative impact on Brazilian children's health - why does food security matter for our future prosperity? Brazilian National Survey (PNDS 2006/07). Food Nutr Bull 37, 585-598.

8. Weigel MM, Armijos RX, Racines M et al. (2016) Association of household food insecurity with the mental and physical health of low-income urban Ecuadorian women with children. J Environ Public Health 2016, 5256084.

9. Pérez-Escamilla R \& Segall-Corrêa AM (2008) Food insecurity measurement and indicators. Rev Nutr 21, Suppl. 0, S15-S26.

10. Kepple AW \& Segall-Corrêa AM (2011) Conceptualizing and measuring food and nutrition security. Cien Saude Colet 16, 187-199.

11. Coates J (2013) Build it back better: deconstructing food security for improved measurement and action. Glob Food Secur 2, 188-194.

12. Jones AD, Ngure FM, Pelto G et al. (2013) What are we assessing when we measure food security? A compendium and review of current metrics. Adv Nutr 4, 481-505.

13. Marques ES, Reichenheim ME, Moraes CL et al. (2015) Household food insecurity: a systematic review of the measuring instruments used in epidemiological studies. Public Health Nutr 18, 877-892.

14. Bickel G, Nord M, Price C et al. (2000) Guide to Measuring Household Food Security - Revised 2000. Alexandria, VA: Food and Nutrition Service, US Department of Agriculture.

15. Pérez-Escamilla R, Segall-Corrêa AM, Maranha LK et al. (2004) An adapted version of the US Department of Agriculture food insecurity module is a valid tool for assessing household food insecurity in Campinas, Brazil. J Nutr 134, 1923-1928.

16. Segall-Corrêa AM, Pérez-Escamilla R, Marin-Léon L et al. (2009) Evaluation of household food insecurity in Brazil: validity assessment in diverse sociocultural settings. In Initiativa América Latina y Caribe Sin Hambre, Concurso redSAN 2007: Memoria Artículos Ganadores, pp. 80-101 [J Ortega, editor]. Santiago: Oficina Regional FAO-Chile.

17. Instituto Brasileiro de Geografia e Estatística (2006) Pesquisa Nacional por Amostras de Domicílios. Segurança Alimentar 2004 (The National Household Sample Survey. Food Security 2004). Rio de Janeiro, RJ: IBGE.

18. Brasil Ministério da Saúde (2008) Pesquisa Nacional de Demografia e Saúde da Criança e da Mulher - PNDS 2006. 
Relatório Final (Brazil National Demographic and Health Survey of Children and Women - PNDS 2006. Final Report). Brasília, DF: Ministério da Saúde.

19. Instituto Brasileiro de Geografia e Estatística (2010) Pesquisa Nacional por Amostras de Domicílios. Segurança Alimentar 2004/2009 (The National Household Sample Survey. Food Security 2004/2009). Rio de Janeiro, RJ: IBGE.

20. Instituto Brasileiro de Geografia e Estatística (2014) Pesquisa Nacional por Amostras de Domicílios. Segurança Alimentar 2013 (The National Household Sample Survey. Food Security 2013). Rio de Janeiro, RJ: IBGE.

21. Brasil, Ministério do Desenvolvimento Social e Combate à Fome \& Secretaria de Avaliação e Gestão da Informação (2014) Quilombos do Brasil: Segurança Alimentar em Territórios (Brazil's Quilombos: Food Security in Brazilian Quilombolas Territories). Cadernos de Estudos Desenvolvimento Social em Debate no 20. Brasília, DF: Ministério do Desenvolvimento Social e Combate à Fome, Secretaria de Avaliação e Gestão da Informação.

22. Fávaro T, Ribas DL, Zorzatto JR et al. (2007) Food security in Terena indigenous families, Mato Grosso do Sul, Brazil. Cad Saude Publica 23, 785-793.

23. Salles-Costa R, Pereira RA, Vasconcellos MTL et al. (2008) Association between socioeconomic factors and food insecurity: a population-based study in the Rio de Janeiro metropolitan area, Brazil. Rev Nutr 21, Suppl. 0, S99-S109.

24. Vianna RPT, Segall-Corrêa AM, Marin-León L et al. (2008) Household food insecurity in municipalities of the Paraiba State, Brazil. Rev Nutr 21, Suppl. 0, S135-S144.

25. Antunes MM, Sichieri R \& Salles-Costa R (2010) Food intake among children under three years of age in an area with high food insecurity. Cad Saude Publica 26, 1642-1650.

26. Guerra LD, Espinosa MM, Bezerra AC et al. (2013) Food insecurity in households with adolescents in the Brazilian Amazon: prevalence and associated factors. Cad Saude Publica 29, 335-348.

27. Cabral CS, Lopes AG, Lopes JM et al. (2014) Food security, income, and the Bolsa Familia program: a cohort study of municipalities in Paraiba State, Brazil, 2005-2011. Cad Saude Publica 30, 393-402.

28. Interlenghi GS \& Salles-Costa R (2015) Inverse association between social support and household food insecurity in a metropolitan area of Rio de Janeiro, Brazil. Public Health Nutr 18, 2925-2933.

29. Gubert MB, Segall-Corrêa AM, Spaniol AM et al. (2016) Household food insecurity in black-slaves descendant communities in Brazil: has the legacy of slavery truly ended? Public Health Nutr 20, 1513-1522.

30. Yuyama LKO, Aguiar JPL, Pantoja L et al. (2007) Nutritional security/insecurity in urban and rural families of Amazonas state: validation of methodology and of information collecting instrument. Acta Amazon 37, 247-252.

31. Hackett $\mathrm{M}$, Melgar-Quiñonez $\mathrm{H}$, Pérez-Escamilla $\mathrm{R}$ et al. (2008) Gender of respondent does not affect the psychometric properties of the Brazilian Household Food Security Scale. Int J Epidemiol 37, 766-774.

32. Melgar-Quiñonez HR, Nord M, Pérez-Escamilla $\mathrm{R}$ et al. (2008) Psychometric properties of a modified US-household food security survey module in Campinas, Brazil. Eur J Clin Nutr 62, 665-673.

33. Segall-Corrêa AM, Marin-León L, Melgar-Quiñonez $\mathrm{H}$ et al. (2014) Refinement of the Brazilian Household Food Insecurity Measurement Scale: recommendation for a 14item EBIA. Rev Nutr 27, 241-251.

34. Ministério do Desenvolvimento Social e Combate à Fome \& Secretaria de Avaliação e Gestão da Informação (2010) Relatório da Oficina Técnica para Análise da Escala Brasileira de Medida Domiciliar de Insegurança Alimentar (Report of the Technical Meeting on the Analysis of the Brazilian Household Food Insecurity Measurement Scale). Nota Técnica n 128/2010.
Brasilia, DF: Ministério do Desenvolvimento Social, Secretaria de Avaliação e Gestão da Informação.

35. Gulliford MC, Mahabir D \& Rocke B (2004) Reliability and validity of a short form household food security scale in a Caribbean community. BMC Public Health 4, 22.

36. Melgar-Quiñonez H, Zubieta AC, Valdez E et al. (2005) Validación de un instrumento para vigilar la inseguridad alimentaria en la Sierra de Manantlán, Jalisco. Salud Publica Mex 47, 413-422.

37. Health Canada, Office of Nutrition Policy and Promotion (2007) Canadian Community Health Survey. Cycle 2.2, Nutrition (2004): Income-Related Household Food Security in Canada. Ottawa: Office of Nutrition Policy and Promotion, Health Canada.

38. Hackett M, Zubieta AC, Hernandez K et al. (2007) Food insecurity and household food supplies in rural Ecuador. Arch Latinoam Nutr 57, 10-17.

39. Rafiei M, Nord M, Sadeghizadeh A et al. (2009) Assessing the internal validity of a household survey-based food security measure adapted for use in Iran. Nutr J 8, 28.

40. Sahyoun NR, Nord M, Sassine AJ et al. (2014) Development and validation of an Arab family food security scale. J Nutr 144, 751-757.

41. US Department of Agriculture, Economic Research Service (2016) Survey tools. https://www.ers.usda.gov/topics/foodnutrition-assistance/food-security-in-the-s/survey-tools/\#adult (accessed January 2017).

42. Ballard TJ, Kepple AW \& Cafiero C (2013) The Food Insecurity Experience Scale: Developing a Global Standard for Monitoring Hunger Worldwide. Rome: FAO.

43. Comité Científico de la ELCSA (2012) Escala Latinoamericana y Caribenã de Seguridad Alimentaria (ELCSA): Manual de Uso y Aplicación. Rome: FAO.

44. Food and Agriculture Organization of the United Nations (2016) Methods for Estimating Comparable Prevalence Rates of Food Insecurity Experienced by Adults Throughout the World. Rome: FAO.

45. General Assembly of the United Nations (2017) Resolution Adopted by the General Assembly on 6 July 2017 (A/RES/71) 313). Adopted Without Reference to a Main Committee (A/71/L.75). New York: UN.

46. Santos LP, Lindemann IL, Motta JV et al. (2014) Proposal of a short-form version of the Brazilian food insecurity scale. Rev Saude Publica 48, 783-789.

47. Reichenheim ME, Interlenghi GS, Moraes CL et al. (2016) A model-based approach to identify classes and respective cutoffs of the Brazilian household food insecurity measurement scale. J Nutr 146, 1356-1364.

48. Interlenghi GS, Reichenheim ME, Segall-Corrêa AM et al. (2017) Modeling optimal cutoffs for the Brazilian household food insecurity measurement scale in a nationwide representative sample. J Nutr 147, 1356-1365.

49. FIRJAN (2018) IFDM 2018: Indice FIRJAN de Desenvolvimento Municipal (IFDM 2018: FIRJAN Municipal Development Index). Rio de Janeiro, RJ: FIRJAN.

50. Instituto Brasileiro de Geografia e Estatística (2013) Pesquisa Nacional por Amostra de Domicílios: volume 33 (The National Household Sample Survey: volume 33). Rio de Janeiro, Brazil: IBGE

51. Clark SL, Muthén B, Kaprio J et al. (2013) Models and strategies for factor mixture analysis: An example concerning the structure underlying psychological disorders. Struct Equ Modeling 20, 681-703.

52. Hagenaars JA \& McCutcheon AL (2002) Applied Latent Class Analysis. Cambridge: Cambridge University Press.

53. Nylund KL, Asparouhov T \& Muthén BO (2007) Deciding on the number of classes in latent class analysis and growth mixture modeling: a Monte Carlo simulation study. Struct Equ Modeling 14, 535-569.

54. Lo Y, Mendell NR \& Rubin DB (2001) Testing the number of components in a normal mixture. Biometrika 88, 767-778. 
55. Asparouhov T \& Muthén B (2012) Using Mplus TECH11 and TECH14 to Test the Number of Latent Classes. Mplus Web Notes no. 14. Los Angeles, CA: Muthén \& Muthén available at https:// www.statmodel.com/examples/webnotes/webnote14.pdf

56. Asparouhov T \& Muthén B (2014) Variable-Specific Entropy Contribution. Los Angeles, CA: Muthén \& Muthén; available at https://www.statmodel.com/download/UnivariateEntropy

57. Muthén LK \& Muthén BO (1998-2017) Mplus User's Guide, 8th ed. Los Angeles, CA: Muthén \& Muthén.

58. Cohen J (1968) Weighted kappa: nominal scale agreement with provision for scaled disagreement or partial credit. Psychol Bull 70, 213-220.

59. StataCorp (2015) Stata Base Reference Manual: Release 15. College Station, TX: Stata Corporation.

60. StataCorp (2017) Stata Statistical Software, Release 15. College Station, TX: Stata Corporation.

61. Wilson M (2005) Constructing Measures. An Item Response Modeling Approach. Mahwah, NJ: Lawrence Erlbaum Associates.
62. Brasil Ministério da Saúde (2008) Protocolos do Sistema de Vigilância Alimentar e Nutricional na Assistência à Saúde (Protocols of the Food and Nutrition Surveillance System in Health Care). Brasília, DF: Ministério da Saúde.

63. Brasil Ministério da Saúde (2013) Política Nacional de Alimentação e Nutrição (National Food and Nutrition Policy). Brasília, DF: Ministério da Saúde.

64. Brasil Ministério da Saúde (2017) Vigitel Brasil 2016: Vigilância de Fatores de Risco e Proteção para Doenças Crônicas por Inquérito Telefônico: Estimativas sobre Frequência e Distribuição Sociodemográfica de Fatores de Risco e Proteção para Doenças Crônicas nas Capitais dos 26 Estados Brasileiros e no Distrito Federal em 2016 (Vigitel Brasil 2016: Brazil Surveillance System of Risk Factors for Chronic Diseases by Telephone Interviews: Frequency and Sociodemographic Distribution of Risk and Protection Factors for Chronic Diseases in the Brazilian Capitals and Federal District in 2016). Brasília, DF: Ministério da Saúde. 